\title{
A FIELD HOSPITAL AT FARNBOROUGH AIR SHOW 1980
}

\author{
COL R CREESE, TD, MB, PhD, L/RAMC \\ St Mary's Ifospital Medical School, London W/2 1PG
}

In the posters which announced the International Air Show there was a helicopter view of the Royal Aircraft Establishment (RAE), Farnborough, with in one corner a group of tents near the far end of the runway (Fig. 1). This is the Ficld Hospital which is set up each year to give medical care, provided in 1980 by 257 (S) General Hospital RAMC (V). The operation is of interest first because of the open-ended character of the commitment: with 250,000 spectators in a small space the medical plan has to include every contingency, from minor mishaps to a major incident, which might involve an aircraft crash inside or outside the airfield or an act by a dissident organisation. The second point of interest for students of military medicine is the nature of the evacuation process: in the event of a major incident the entire organisation of rear evacuation by road and air is directed from the Command Post of the Field Hospital - a control which is rarely achieved by the medical services in other situations. And the third point is that personnel in 1980 were from a volunteer unit and this major operation was in addition to Annual Camp.

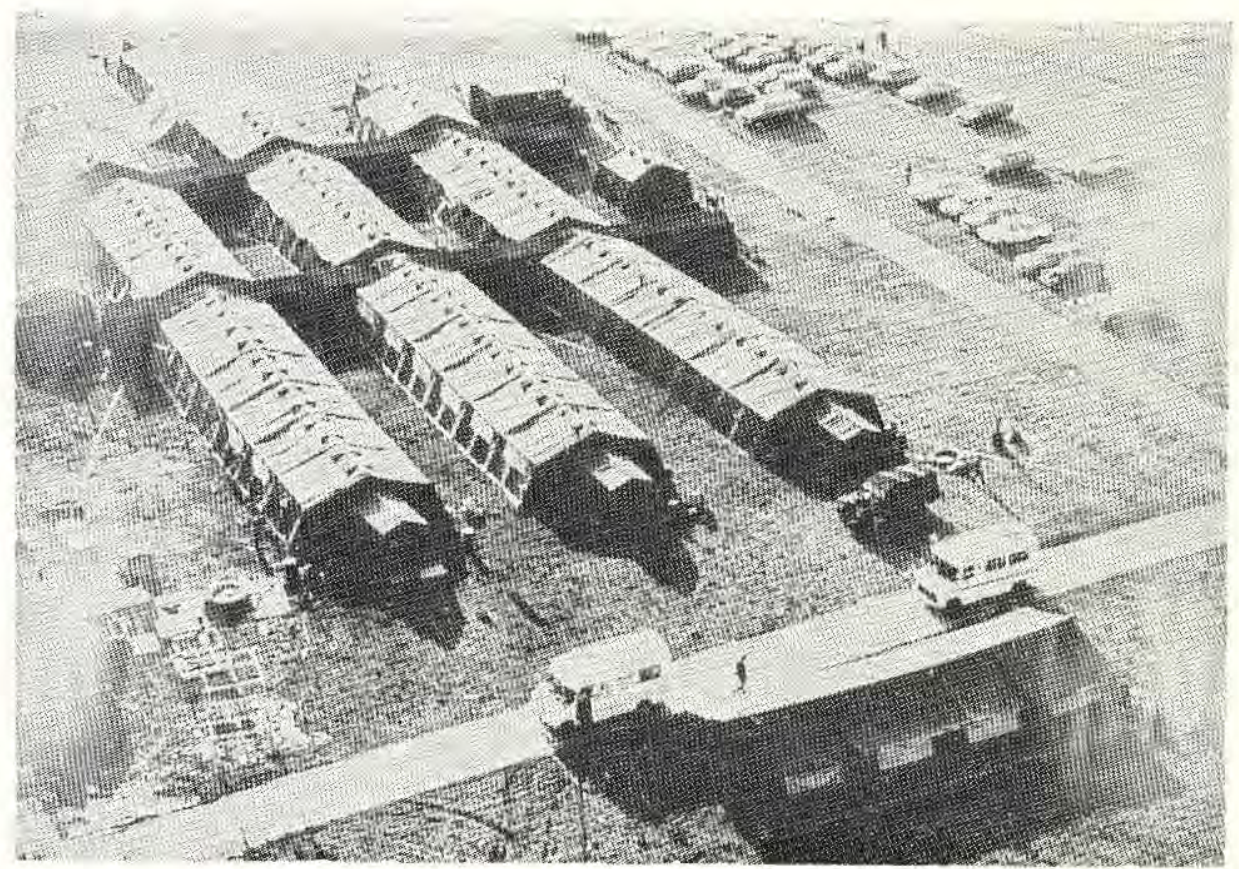

Fig. 1. Air photograph of the Field Hospital at Farnborough Air Show 1980 
The Field Hospital formed part of the comprehensive medical plan prepared by RAE medical services, whose Senior Medical Officer was Dr G E Morley. This involved the provision of routine care for illness and accident among staff and visitors, arranged by the British Red Cross and RAE Medical Services. For a major incident at the Air Show the civil and military organisations would all come under control of the Emergency Liaison Centre (ELC) headed by a senior police officer. On each of the public days of the Air Show an impressive parade took place of firefighting and rescue vehicles and ambulances, with the helicopters which would have a similar role in an aircraft accident.

The hospital was stationed at the end of the runway, adjacent to an exit from the airfield. Casualties south of the runway would be collected and broughit to reception by Red Cross Ambulances and the RAE Ambulance Service had a similar responsibility north of the runway.

The facilities provided were 'tailor-made' to meet the Farnborough specification. The functions of the Field Hospital were:

a. Classification of casualties. b. Control of evacuation by road and air. c. Retention of casualties if saturation of evacuation plan occurred. d. Emergency resuscitation and theatre facilities.

The hospital included a surgical team and theatre facilities but it was not expected to deal with casualties classified as Priority I or Priority II. Road transport from the Field Hospital was organised by the Hampshire Health Authority Ambulance Service, and air evacuation was provided by three helicopters which were rigged for aeromedical use, and by ' $A$ ' Flight of No 1 Aeromedical Evacuation Unit RAF (AEU). Arrangements had been made with twelve hospitals which included the Cambridge Military Hospital, Royal Naval Hospital, Haslar and civilian hospitals which ranged from Slough to Southampton. Each hospital was contacted daily to ensure that surgical teams were avaliable: each helicopter pilot was provided with maps and air photographs of pre-arranged landing strips. It was assumed that the Field Hospital would be capable of handling a major disaster involving up to 100 seriously injured casualties: Priority $I$ and Priority II cases would be evacuated by air and road, and the remainder would be held for later disposal.

The diagram shows the layout of the Field Hospital (Fig. 2). It had a large Reception area capable of accepting 50 patients, an eight-bed Resuscitation department, a two-table Theatre complete with CSSD section, two 25-bed wards and a large Evacuation department. Tentage and equipment were available for 50 extra beds and No 1 AEU could provide more if necessary.

Tentage was the new light-weight, aluminium framed pattern with internal white lining. It was erected in a pattern so that movement was always under cover by using corridors and four-way connections. An aluminium planked portable trackway made a complete road around the area so that a one-way circuit could be adapted for ambulances. Electrical power was provided by mains electricity from the Airfield circuits backed up by emergency generation. A scaffold tower was created with a 1,000 gallon water tank and water was piped to all departments. Hot water was provided by the ubiquitous soyer stoves. A complete 


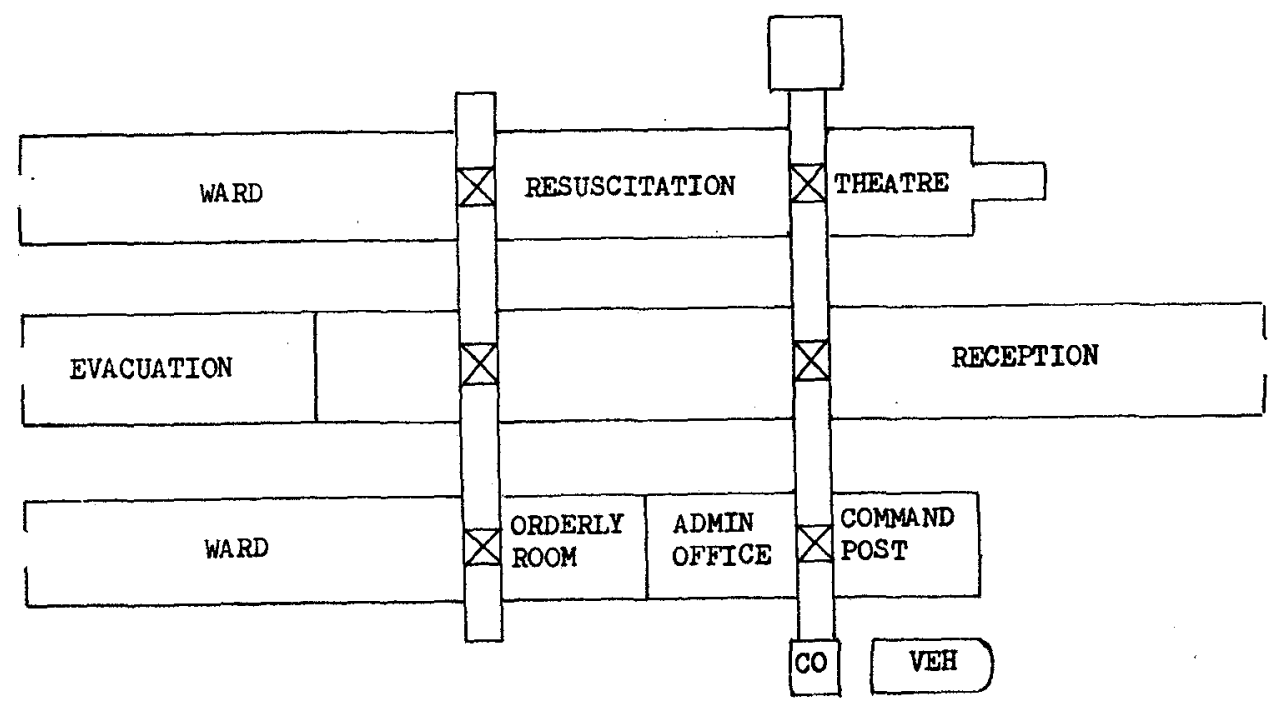

Fig. 2. Diagram of the Field Hospital at Farnborough Air Show 1980

25-line internal telephone system and a vehicle-mounted switchboard was provided by 47 (Middlesex Yeomanry) Signal Sqn (V) which gave communication between all deparments. A public address system with internal and external speakers was installed and its worth was proved for the controlling staff.

The Hospital had a guardroom with an information desk to deal with public enquiries and was surrounded by a security fence. Mortuary facilities were provided. The nerve centre of the Hospital was the Command Post (CP). Continuously manned by a team from the Unit with Police and Ambulance representatives, it was able to control all activity within the operational complex. A command vehicle was located outside to give radio communication to all ambulances of the Hampshire Ambulance Service who provided road evacuation. Telephone communications were installed to give external lines to Hospitals, Police and Medical Services at the ELC. Display boards gave visual information on patients, bed levels, situation maps and ambulances. The administration area was separated from the operations area and provided accommodation and food, messes and stores for staff and casualties. No 1 AEU RAF was stationed adjacent to the Hospital with landing pads for the helicopter, and accommodation, and members of this unit helped man the Evacuation Department.

In all there were 15 tons of canvas to erect, 30 tons of general stores and 10 tons of medical equipment which was unloaded and assembled to make up the Hospital. Eager-beaver fork-lift trucks and RCT vehicles helped to make this task easier. Other Arms of the Service co-operated - we needed portable track from RE units and they installed the water system; lighting equipment and generators came from the RAOC; telephones from R Signals and many other 
items too numerous to mention were readily given to make the Hospital viable. The equipment for Resuscitation included ventilators, laryngoscopes, airways, oxygen delivery systems and intravenous fluids and was much appreciated as training aids. Those on the site had a strenuous time and the training programme included rehearsals. The principal hazard was fire and extensive equipment was provided to meet this problem. Daily fire practice and exercises with the Fire Brigade were carried out.

Planning for a major exercise of this kind has to start early in the case of Volunteer forces because of the nature of other commitments, and in practice the outline organisation and key responsibilities were decided six months previously. To cover the five-day Air Show and to allow time for setting up, rehearsals and run-down the site had to be occupied for two weeks, and since few volunteers can take this time from work the attendance was staggered to cover the period. The programme was only possible because of the endeavours of the permanent staff, whose efforts made it possible to realise the potential of volunteer forces.

The exercise was popular with the soldiers, who had a ring-side view of the Air Show and also realised that they were making a worthwhile contribution on a public occasion. For those in the Command Post who had to prepare for many different contingencies it was indeed a relief when the stand-down came without the plans having to be tested.

\section{Acknowledgements}

I wish to thank Col R M Burton and Maj J K Dickson for help in preparation of this article. 